\title{
Relative Efficiency of Pure Cultures of Different Species of Cellulolytic Rumen Bacteria in Solubilizing Cellulose in vitro
}

\author{
By N. O. VAN GYLSWYK AND J. P. L. LABUSCHAGNE \\ National Chemical Research Laboratory, \\ South African Council for Scientific and Industrial Research-Onderstepoort \\ Joint Unit for Research on Digestion and Metabolism in Ruminants, \\ P.O. Box 395, Pretoria, South Africa
}

(Accepted for publication 17 March 197I)

\begin{abstract}
SUMMARY
The rates at which two strains each of four species of cellulolytic rumen bacteria could grow on and solubilize ball-milled filter paper were compared in vitro. Strains of Ruminococcus albus solubilized it most rapidly, followed by $R$. flavefaciens. Butyrivibrio fibrisolvens showed consistently low rates of solubilization while strains of Cillobacterium cellulosolvens maintained on cellobiose-containing medium gradually lost their ability to solubilize cellulose. Cellulolysis could not be restored by successive transfers to media each containing one of different cellulose oligosaccharides. Strains of $R$. albus and $R$. flavefaciens grew almost as rapidly in cellulose- as in cellobiose-containing media, while $B$. fibrisolvens strains grew better in medium with cellobiose. On this basis the ruminococci were termed true cellulolytic bacteria.
\end{abstract}

\section{INTRODUCTION}

The numbers and proportions of different species of cellulolytic bacteria in the rumens of sheep conditioned to various high-roughage diets have been studied for several years (Gilchrist \& Kistner, I962; Kistner \& Gouws, I964; Gouws \& Kistner, I965; van Gylswyk, 1970). Such numbers and proportions do not necessarily reflect the relative importance of the different species in breaking down cellulose in the rumen as there may exist large differences between species in the rates of breakdown of dietary fibre. Kock \& Kistner (I969) determined the extent of cellulose and hemicellulose breakdown by pure cultures of some species of rumen bacteria. A comparison of rates of degradation is equally important in assessing the efficiency of species in the digestion of high-fibre diets. Therefore the rates of cellulose breakdown by representative strains of species from the sheep rumen were compared.

Two strains each of Ruminococcus albus, R. flavefaciens, Butyrivibrio fibrisolvens and Cillobacterium cellulosolvens were selected for study in detail after a preliminary screening of a number of isolates of each species to determine the degree of variability in cellulolytic activity between and within species. To measure the rate of cellulolysis by these organisms under the most favourable circumstances it was decided to use ball-milled Whatman no. I filter paper as the cellulose substrate, since Halliwell \& Bryant (1963) found that, of several forms of cellulose tested, this material was most readily degraded by different speciesof cellulolytic rumen bacteria. In addition, growth was compared in medium containing either cellulose or cellobiose to determine whether degradation of cellulose was a rate-limiting step in the growth of any species. 


\section{METHODS}

Bacteria. The strains used were described by van Gylswyk \& Hoffman (1970) and van Gylswyk \& Roché (1970).

Media. The basic composition of media used to culture and maintain the organisms was the same as that described by van Gylswyk \& Hoffman (1970). Rumen fluid (40\%, v/v) was included in all the media and was clarified by centrifuging at $23,000 \mathrm{~g}$ for $2 \mathrm{~h}$. in order to remove all particulate nitrogen-containing material. Cellulose substrate was prepared from shredded Whatman no. I filter paper as a $2 \%(\mathrm{w} / \mathrm{v})$ suspension in deionized water by grinding in a ball mill for 7 days. The complete medium containing cellulose was heat-sterilized. Cellobiose was added as a Millipore filter-sterilized aqueous solution to heat-sterilized basal medium. Maintenance slopes contained $0.5 \%$ cellobiose. In the first test, the medium for production of inoculum contained $0.0 \mathrm{I} \%$ cellobiose and $\mathrm{I} \%$ filter paper cellulose and the medium in which growth and cellulose degradation was determined contained $0.5 \%$ cellulose.

The inoculation medium for the second test contained a growth-limiting concentration of $0.1 \%$ cellobiose. This was done to obtain approximately equal quantities of organisms of the different isolates within a limited incubation period, which would not have been possible if cellulose had been used as substrate. The low concentration of cellobiose also prevented a rapid loss of viability as the result of excessive accumulation of metabolic products. The media in which growth rates and rates of cellulose degradation were determined were prepared from the same batch of basal medium. The respective substrates were added in such concentration to give $\mathrm{I} \%$ after inoculation.

In tests made to attempt to restore cellulolytic activity to a strain of Cillobacterium cellulosolvens the inoculum was grown in medium containing $0.1 \%$ cellobiose. After transfer the organisms were passaged for 8 days, in each of a series of media containing $0.1 \%$ of one of the following: cellobiose, -triose, -tetraose, -pentaose, -hexaose, -dextrin or cellulose. The cellulose oligosaccharides were prepared according to Miller (1963). The eluent fractions were tested for purity by thin-layer chromatography on Kieselgur G (according to Stahl, E. Merck AG, Darmstadt, Germany) with butanol/pyridine/water (65:20:15; Weill \& Hanke, 1962) as solvent and ethanol/sulphuric acid/anisaldehyde as spray reagent (Stahl \& Kaltenbach, 1961).

Preparation of inocula. For the first test actively growing bacteria from maintenance agar slopes were transferred in about $0.5 \mathrm{ml}$. fluid to bottles containing $25 \mathrm{ml}$. of medium. Inoculum was removed after $24 \mathrm{~h}$. if good growth had occurred as judged by visual disappearance of cellulose, or otherwise up to $72 \mathrm{~h}$. later if no such disappearance was obvious. Twenty ml. of the inoculum was added to $100 \mathrm{ml}$. of test medium.

For the second, main, experiment actively growing bacteria were transferred from slopes to bottles containing I Io ml. medium. Inocula were grown for 20 to $24 \mathrm{~h}$. to give similar concentrations of bacteria. Fifty $\mathrm{ml}$. portions of the inoculum were added to $150 \mathrm{ml}$. of test medium prewarmed to $38^{\circ}$. All cultures were incubated at $38^{\circ}$.

Determination of cellulose. Fifteen ml. samples in test tubes were immediately immersed in boiling water for Io min. to inactivate cellulase. The contents were filtered through weighed glass-fibre pads (Whatman $2.5 \mathrm{~cm}$. GF/B; W. \& R. Balston Ltd, London) in a $15 \mathrm{ml}$. Millipore Microanalysis Filter Holder. The residual cellulose was washed and dried, following the method of Halliwell (1957), after which the pads plus cellulose were weighed.

Determination of non-ammonia nitrogen. Bacterial concentrations in the cultures were measured as non-ammonia nitrogen. Samples ( $10 \mathrm{ml}$.) were placed in $30 \mathrm{ml}$. Kjeldahl flasks 
and $0.5 \mathrm{ml}$. of $40 \%(\mathrm{w} / \mathrm{v}) \mathrm{KOH}$ was added. The flasks were placed in a vacuum oven and the contents evaporated to dryness at about $80^{\circ}$ to drive off ammonia. Nitrogen was then determined using a Kjeldahl procedure.

\section{RESULTS}

In the first test four strains of Ruminococcus albus solubilized between 400 and $495 \mathrm{mg}$. cellulose / $100 \mathrm{ml}$. medium in $24 \mathrm{~h}$. and six strains of $R$. flavefaciens solubilized 250 to $310 \mathrm{mg}$. Five strains of Butyrivibrio fibrisolvens solubilized only 30 to $70 \mathrm{mg}$. of cellulose. The solubilization produced by three strains of Cillobacterium cellulosolvens was the most variable,

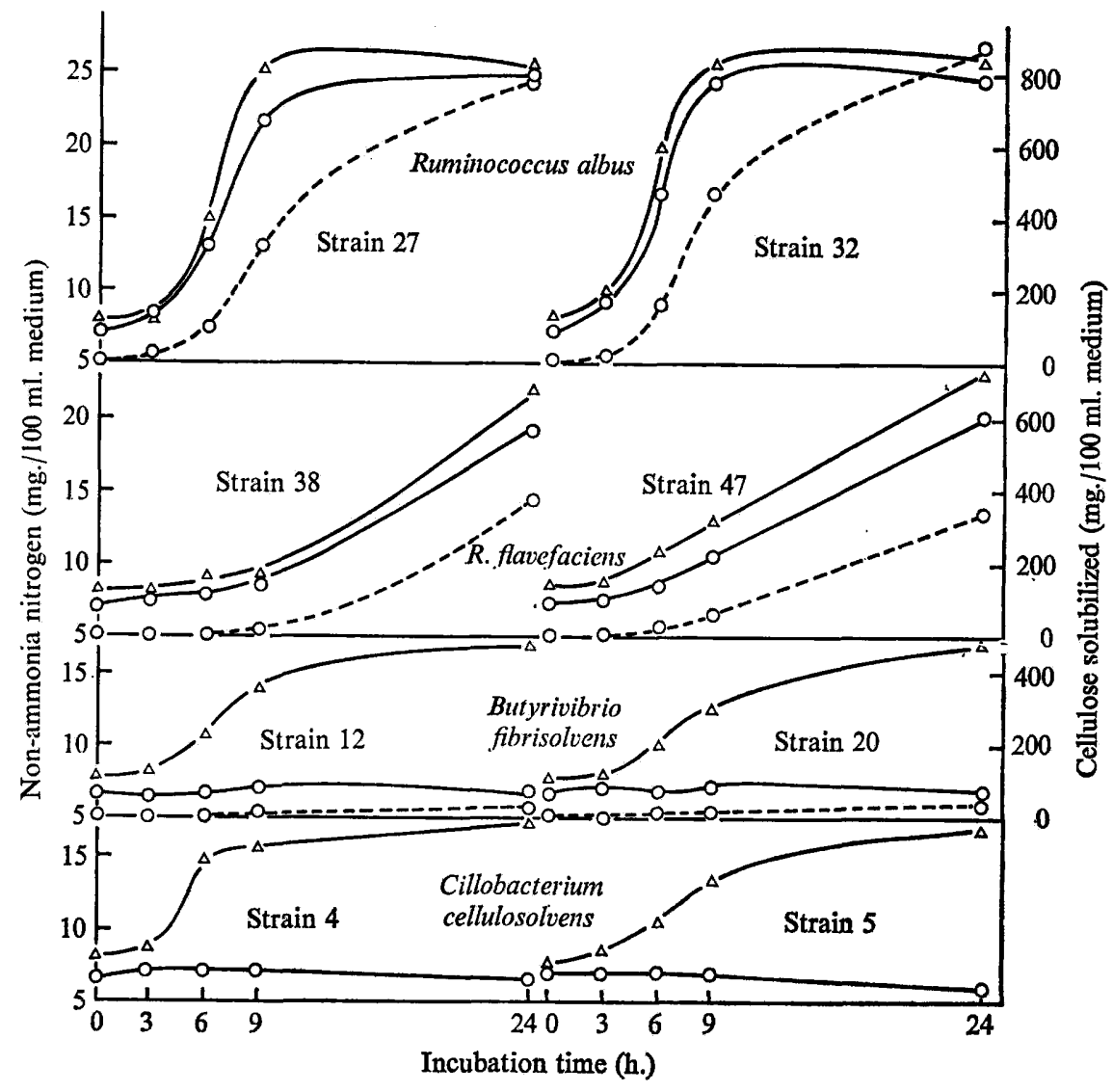

Fig. I. Non-ammonia nitrogen synthesis (bacterial growth) in medium containing $40 \%(\mathrm{v} / \mathrm{v})$ rumen fluid and $\mathrm{I} \%$ cellobiose $(-\triangle \longrightarrow)$ or I \% ball-milled filter paper cellulose $(-\mathrm{O}-)$ and solubilization of cellulose (--- ○---) in the latter medium by two strains of each of four different species of cellulolytic rumen bacteria.

from 80 to $220 \mathrm{mg}$. of cellulose being solubilized, and it appeared that the cillobacteria were gradually losing their ability to solubilize cellulose. For this reason strain 4 , which had been subjected to at least one transfer less than the strains used for the first test, was included in the second test. One strain each of $R$. flavefaciens var. lacticus and a group 4 strain of Ruminococcus (van Gylswyk \& Roché, 1970) solubilized relatively small quantities of cellulose ( 45 to $55 \mathrm{mg}$. $/ 24 \mathrm{~h}$.). This tends to confirm that they are distinct from both $R$. albus and $R$. flavefaciens (van Gylswyk \& Roché, 1970). 
Two representative strains from those used in the first test were then studied in more detail. Fig. I shows results from the second test on solubilization of cellulose and growth on cellulose and cellobiose over a period of $24 \mathrm{~h}$. The maximum rate of cellulose degradation was about $100 \mathrm{mg}$./h. for Ruminococcus albus, but in the case of $R$. flavefaciens it was barely $25 \mathrm{mg}$./h. The growth rate of the $R$. albus strains was considerably greater than that of the $R$. flavefaciens strains in both media. The Butyrivibrio strains grew poorly in cellulosecontaining medium and cellulose breakdown was very slow, while growth in cellobiosecontaining medium was much more rapid. The quantities of cellulose solubilized over $24 \mathrm{~h}$. were similar to those found previously. The cillobacteria showed no measurable cellulolysis over $24 \mathrm{~h}$. and very little growth in medium containing cellulose, whereas growth was considerable in medium with cellobiose. These strains had progressively lost their cellulolytic activity after alternately storing and culturing on cellobiose/rumen-fluid agar slopes, but activity of strain 5 was still considerable when the first test was made. It is possible that growth of inocula in cellobiose-containing liquid medium for the main test may have hastened the loss of cellulolytic activity. It was thought that cellulolytic activity could perhaps be induced by a soluble hydrolysis product of cellulose. Strain I of Cillobacterium cellulosolvens (van Gylswyk \& Hoffman, 1970), which was found to have lost cellulolytic activity, was used. Microscopic examination of samples of media containing cellulose or one of the cellulose oligosaccharides, taken after the eighth transfer, showed that growth had taken place in all the media except that containing cellulose. Bacteria tested for cellulolytic activity at the same time gave negative results.

\section{DISCUSSION}

The growth conditions created in the present work showed at least a fair resemblance to those existing in the rumen in that active growth of relatively fastidious organisms was obtained. Conditions were, however, not ideal if loss of cellulolytic activity of the cillobacteria is considered a criterion. This loss may have resulted from lack of certain growth factors or from culture in cellobiose media. Soon after isolation it was found that whereas the cillobacteria could grow in a medium in which Trypticase/yeast extract replaced rumen fluid (van Gylswyk \& Hoffman, 1970), cellulolysis was very slow in this medium when compared with cellulolysis in medium containing rumen fluid.

A different situation exists in the case of Ruminococcus flavefaciens which did not grow as rapidly as $R$. albus, but cellulolytic activity was not impaired as similar growth rates were found in cellobiose- and cellulose-containing media. This difference in growth rates between the two species has constantly been observed and may be due to differences in genetic makeup or else due to differences in nutrient requirements.

It did not appear that the Butyrivibrio strains used in this study had lost cellulolytic activity. Cellulolysis was always difficult to detect visually in liquid media containing rumen fluid and filter paper cellulose (van Gylswyk, 1968) and in work done before the present study quantitative determinations of cellulose degradation gave very similar results to those reported here.

Ruminococcus albus is clearly the most active in vitro of the cellulolytic bacteria isolated from the rumens of sheep fed low-protein teff hay diets. Numerically these bacteria shared predominance with $R$. flavefaciens (van Gylswyk, 1970). Both these species can be regarded as 'true' cellulolytic inhabitants of the rumen when judged by their ability to grow nearly as well with cellulose as with a breakdown product of cellulose, cellobiose. Cellulolysis is, therefore, not a rate-limiting step in growth. By comparison the butyrivibrios can hardly be 
regarded as significant cellulose digesters when judged by the rate of cellulose solubilization in vitro, even though these bacteria may occur as a relatively large proportion of the cellulolytic flora (Gilchrist \& Kistner, 1962; van Gylswyk, 1970). The greater growth rate in medium with cellobiose indicates that cellulolysis is the growth-rate limiting step. Kock \& Kistner (1969) also found, when studying the extent of solubilization of cellulose, that the butyrivibrios were less efficient than the ruminococci. This is further illustrated by other data on butyrivibrios. A strain was described by Hungate (1950) as the 'less actively cellulolytic rumen rod' and the majority of Butyrivibrio strains described are not cellulolytic. For instance, only three out of 48 strains of butyrivibrios were shown by Bryant \& Small (1956) to be cellulolytic. However, Bryant (I959) felt that there was reason to believe that these bacteria lost cellulolytic activity when cultured on media containing glucose and cellobiose. The importance of the cillobacteria in solubilizing cellulose could not be estimated. However, they are of relatively low incidence in the rumen.

The authors wish to thank Dr A. Kistner and Dr H. M. Schwartz for advice and interest in this work.

\section{REFERENCES}

BRYANT, M. P. (1959). Bacterial species of the rumen. Bacteriological Reviews 23, I25-153.

Bryant, M. P. \& Small, N. (1956). The anaerobic monotrichous butyric acid-producing curved rod-shaped bacteria of the rumen. Journal of Bacteriology 72, $16-21$.

GIrCHRIST, F. M. C. \& KISTNER, A. (1962). Bacteria of the ovine rumen. I. The composition of the population on a diet of poor teff hay. Journal of Agricultural Science, Cambridge 59, 77-83.

Gouws, L. \& KistNer, A. (1965). Bacteria of the ovine rumen. IV. Effect of change of diet on the predominant type of cellulose-digesting bacteria. Journal of Agricultural Science, Cambridge 64, 5 I-57.

Halliwell, G. (1957). Cellulolysis by rumen micro-organisms. Journal of General Microbiology 17, 153-165.

Halliwell, G. \& BRYANT, M. P. (1963). The cellulolytic activity of pure strains of bacteria from the rumen of cattle. Journal of General Microbiology 32, 44I-448.

Hungate, R. E. (1950). The anaerobic mesophilic cellulolytic bacteria. Bacteriological Reviews 14, I-49.

KistNer, A. \& Gouws, L. (1964). Cellulolytic cocci occurring in the rumen of sheep conditioned to lucerne hay. Journal of General Microbiology 34, 447-458.

KocK, S. G. \& KISTNER, A. (1969). Extent of solubilization of $\alpha$-cellulose and hemicellulose of low-protein teff hay by pure cultures of cellulolytic rumen bacteria. Journal of General Microbiology 55, 459-462.

MILLER, G. L. (1963). Cellodextrins. Hydrolysis of cellulose to oligosaccharides. In Methods in Carbohydrate Chemistry. Vol. 3. Cellulose. Edited by R. L. Whistler. New York: Academic Press.

Stahl, E. \& Kaltenbach, U. (196I). Dünnschicht-Chromatographie. VI. Mitteilung. Spurenanalyse von Zuckergemischen auf Kieselgur G-Schichten. Journal of Chromatography 5, 35I-355.

van GylswyK, N. O. (1968). The Cellulolytic Rumen Bacteria of Sheep Fed Supplemented Hay Diets. M.Sc. Thesis, University of Pretoria.

vaN GYLSWYK, N. O. (1970). The effect of supplementing a low-protein hay on the cellulolytic bacteria in the rumen of sheep and on the digestibility of cellulose and hemicellulose. Journal of Agricultural Science, Cambridge 74, $169-180$.

VAN GYLSWYK, N. O. \& HoffMAN, J. P. L. (1970). Characteristics of cellulolytic cillobacteria from the rumens of sheep fed teff (Eragrostis tef) hay diets. Journal of General Microbiology 6o, 381-386.

vaN GyLswYK, N. O. \& RochÉ, C. E. G. (1970). Characteristics of Ruminococcus and cellulolytic Butyrivibrio species from the rumens of sheep fed differently supplemented teff (Eragrostis tef) hay diets. Journal of General Microbiology 64, II-17.

WeILL, C. E. \& HANKE, P. (1962). Thin-layer chromatography of malto-oligosaccharides. Analytical Chemistry 34, 1736-1737. 